\title{
PERBANDINGAN PELAKSANAAN INFORMED CONSENT DI IRNA BEDAH FLAMBOYAN DENGAN IRNA BEDAH GLADIOL RSUD. DR. SOETOMO SURABAYA BERDASARKAN STANDAR KONSIL KEDOKTERAN INDONESIA (KKI)
}

\author{
Oleh: \\ Eka Wilda Faida \\ Dosen STIKES Yayasan RS Dr. Soetomo Surabaya \\ Email : ekawildafaida@gmail.com
}

\begin{abstract}
ABSTRAK
Informed consent merupakan persetujuan yang diberikan kepada pasien setelah diberikan penjelasan oleh dokter mengenai tindakan kedokteran. Tujuan dari penelitian ini diantaranya adalah untuk membandingkan prosedur pelaksanaan Informed To Consent, Informed Consent, Informed Refusal antara Irna Bedah Gladiol dengan Irna Bedah Flamboyan. Hasil penelitian menunjukkan bahwa Informed To Consent di Irna Bedah Gladiol lebih baik dibandingkan dengan Irna Bedah Flamboyan karena di Irna Bedah Gladiol yang tidak sesuai dengan standar KKI adalah hanya 5\% lebih rendah 9\% dibandingkan yang ada di Irna Bedah Flamboyan yaitu sebanyak 14\%. Pada aspek Informed Consent di Irna Bedah Gladiol lebih buruk dibandingkan dengan Irna Bedah Flamboyan karena di Irna Bedah Gladiol yang tidak sesuai dengan standar KKI adalah sebanyak 6\% lebih tinggi $1 \%$ dibandingkan yang ada di Irna Bedah Flamboyan yaitu hanya sebanyak 5\%. Sedangkan Informed Refusal di Irna Bedah Gladiol adalah sama dengan Irna Bedah Flamboyan memiliki prosedur penolakan tindakan medis yang sudah baik karena memiliki nilai $100 \%$ sesuai berdasarkan standar KKI. Saran yang dapat diberikan peneliti adalah Perlu di lakukan evaluating, controlling dan monitoring agar menghasilkan kriteria penilaian yang sangat baik dan bermanfaat besar bagi rumah sakit. Perlu dilakukannya pemberian informasi secara tertulis. Misal, penempelan Leaflet yang menjelaskan cara pengisian berkas rekam medis maupun form persetujuan tindakan harus diisi dengan jelas, lengkap, dan benar yang ditujukan kepada pasien maupun peraturan yang menjelaskan tentang Informed Consent.
\end{abstract}

Kata Kunci : Informed consent, Konsil Kedokteran Indonesia (KKI), Irna bedah

\section{ABSTRACT}

Informed consent given to patients after the explanation given by the physician on the medical action. Purposed to compare the procedures including implementation Informed to Consent, Informed Consent, Informed Refusal between Gladiolus Surgery and Flamboyan Surgery. The results showed that Informed to Consent in Gladiolus Surgery better than Flamboyan Surgery because Gladiolus Surgery that does not comply with the standards of KKI (Indonesia Medicine Council) is only 5\% lower than 9\% from Flamboyan Surgery is 14\%. Aspect Informed Consent in Gladiolus Surgery worse than Flamboyan Surgery because Gladiolus Surgery that does not comply with the standards of KKI 6\% higher than Flamboyan is only 5\%. While Informed Refusal in Gladiolus Surgery is same as the Flamboyan Surgery, Surgical procedures medical treatment denial is good because it has a corresponding value of $100 \%$ standards-based KKI. Advice can be given by researchers is 
should be done evaluating, controlling and monitoring in order to produce the assessment criteria were very nice and helpful great for hospital. The provision of information in writing. Explains how to fill Medical Record and consent form must be filled with a clear, complete, and completely devoted to patients and Regulations describes Informed Consent.

Keywords: Informed consent, Indonesia Medical Council (KKI), Surgical inpatient unit

\section{PENDAHULUAN}

Dalam memberikan pelayanan kesehatan baik yang bersifat klinis, operatif, rawat jalan, rawat inap, kuratif dan rehabilitatif tentunya membutuhkan persetujuan tertulis (Informed Consent) dimana persetujuan tertulis ini di dalam ketentuan dari Standar Konsil Kedokteran Indonesia (KKI) terdiri dari Informed to consent, Informed consent, dan informed refusal. Dalam penerapannya di rumah sakit terutama di rumah sakit kelas A seperti di RSUD.Dr.Sutomo Surabaya yang bersifat complicated dimana seluruh unsur pelayanan kesehatan yang tersedia hal tersebut tidaklah mudah perlu menjadi perhatian utama dan kerjasama yang baik dari semua pihak agar pelaksanaan tersebut dapat berjalan sesuai dengan standar dan peraturan yang telah ditentukan.

Appelbaum seperti dikutip Guwandi (1993) menyatakan bahwa "Informed Consent bukan sekedar formulir persetujuan yang didapat dari pasien, melainkan proses komunikasi. Tercapainya kesepakatan antar dokter dengan pasien merupakan dasar dari seluruh proses tentang Informed Consent. Formulir itu hanya merupakan pengukuhan atau pendokumentasian dari apa yang telah disepakati (Informed consent is a process, not an event). Namun, tidak selamanya pasien atau keluarga pasien setuju dengan tindakan medik yang akan dilakukan oleh dokter".

Mengingat betapa pentingnya Informed to consent, Informed consent dan Informed refusal di dalam memberikan pelayanan medis maupun penunjang medis kepada pasien dan keluarganya, maka kami sebagai peneliti merasa sangat perlu bertanggung jawab terhadap pelaksanaan ini di RSUD Dr. Soetomo Surabaya khususnya pada Irna Bedah Flamboyan dan Irna Bedah Gladiol didalam memberikan pelayanan kesehatan yang bermutu dan berguna serta menghasilkan informasi yang tepat dan akurat tentunya harus didukung oleh pengisian setiap lembar rekam medis terutam pada Informed to consent, Informed consent dan Informed refusal yang baik dan akurat. Apabila dari lembaran tersebut tidak diisi dengan baik dan lengkap, maka akan mengakibatkan informasi yang ada didalam rekam medis menjadi tidak tepat, tidak akurat dan tidak sah atau tidak legal. 
Dengan melihat dari 10 berkas rekam medis pasien ruang $\mathrm{F} 1, \mathrm{~F} 2$, dan $\mathrm{F} 3$ masih terdapatnya ketidak sesuaian pada Prosedur Pelaksanaan Informed To Consent, Informed Consent, dan Informed Refusal yang berkaitan dengan masalah pada Prosedur Pelaksanaan Informed To Consent, Informed Consent, dan Informed Refusal pada IRNA Bedah Flamboyan dan Galdiol, maka penulis tertarik untuk melakukan penelitian dan menuangkan dalam bentuk karya tulis ilmiah dengan tema "Perbandingan Pelaksanaan Informed Consent di Irna Bedah Flamboyan dengan Irna Bedah Gladiol RSUD. Dr. Soetomo Surabaya Berdasarkan Standar Konsil Kedokteran Indonesia (KKI)". Tujuan penelitian ini adalah Mengukur Perbandingan Pelaksanaan Informed Consent di Irna Bedah Flamboyan dengan Irna Bedah Gladiol RSUD. Dr. Soetomo Surabaya Berdasarkan Standar Konsil Kedokteran Indonesia (KKI).

\section{TINJAUAN PUSTAKA}

\section{Rumah Sakit}

Menurut WHO merupakan suatu badan usaha yang menyediakan pemondokan yang memberikan jasa pelayanan medik jangka pendek dan jangka panjang yang terdiri atas tindakan observasi, diagnostik, terapeutik, dan rehabilitatif untuk orang-orang yang menderita sakit, terluka dan untuk mereka yang mau melahirkan. Di samping itu, rumah sakit juga menyediakan pelayanan atas dasar berobat jalan kepada pasienpasien yang bisa langsung pulang.

\section{Rekam Medis}

Menurut Undang-Undang RI Nomor 29 tahun 2004 tentang Rekam Medis Pasal 46 Rekam Medis yaitu “ Berkas yang berisikan catatan dan dokumen tentang identitas pasien, pemeriksaan, pengobatan, tindakan dan pelayanan lain yang telah diberikan kepada pasien".

\section{Informed Consent}

Menurut Undang-Undang RI

Nomor 29 tahun 2004 tentang Persetujuan Tindakan Kedokteran atau Kedokteran Gigi Pasal 45 Persetujuan Tindakan Kedokteran atau Kedokteran Gigi adalah “ Bahwa setiap tindakan kedokteran atau kedokteran gigi yang akan dilakukan oleh dokter atau dokter gigi terhadap pasien harus mendapat persetujuan ".

\section{Fungsi Informed Consent}

Menurut J. Guwandi, SH fungsi dari informed consent adalah :

1) Promosi dari hak perorangan.

2) Proteksi dari pasien dan subjek.

3) Mencegah terjadinya penipuan dan paksaan.

4) Menimbulkan rangsangan kepada profesi medis untuk mengadakan intropeksi diri terhadap diri sendiri. 
Eka Wilda F, Perbandingan Pelaksanaan Informed Consent Di Irna Bedah Gladiol Dengan Irna Bedah Flamboyan RSUD. Dr. Soetomo Surabaya Berdasarkan Standar Konsil Kedokteran Indonesia (KKI)

5) Promosi dan keputusan-keputusan rasional.

6) Keterlibatan masyarakat (dalam memajukan prinsip otonomi sebagai suatu nilai sosial dan mengadakan pengawasan dalam penyelidikan biomedik).

\section{KKI (Konsil Kedokteran Indonesia)}

Dalam Konsil Kedokteran Indonesia (KKI) (2006) Persetujuan tindakan kedokteran atau kedokteran gigi yang sering disebut juga Informed Consent:" merupakan persetujuan pasien atau yang sah mewakilinya atas rencana tindakan kedokteran atau kedokteran gigi yang diajukan oleh dokter atau dokter gigi, sehingga dapat ditarik kembali setiap saat persetujuan tindakan kedokteran dan kedokteran gigi merupakan proses sekaligus hasil dari suatu komunikasi yang efektif antara pasien dengan dokter atau dokter gigi dan bukan sekedar penandatanganan lembar persetujuan ".

\section{METODE PENELITIAN}

Jenis penelitian ini menggunakan metode penelitian deksriptif observasional, yaitu penelitian yang diarahkan untuk menguraikan suatu keadaan didalam suatu komunitas atau masyarakat dilakukan untuk menilai suatu program yang sedang atau sudah dilakukan. Penelitian ini dilaksanakan pada bulan September-
November 2014 di IRNA Bedah Flamboyan dan IRNA Bedah Gladiol RSUD Dr. Soetomo Surabaya. Populasi adalah kerangka sampel (daftar nama anggota populasi), dalam penelitian ini jumlah lembar informed to consent, informed consent, dan informed refusal.

Teknik pengambilan sampel dalam penelitian ini menggunakan teknik pengambilan simple random sampling atau pengambilan sampel secara acak sederhana yaitu setiap anggota atau unit dari populasi mempunyai kesempatan yang sama untuk di seleksi sebagai sampel.

Perhitungan jumlah sampel penelitian diambil menurut Notoatmodjo (2005) yaitu sebagai berikut :

$$
n=\frac{\mathrm{N}}{1+\mathrm{N}\left(d^{2}\right)}
$$

Keterangan:

$$
\begin{array}{ll}
n & =\text { Ukuran Sampel } \\
\mathrm{N} & =\text { Ukuran Populasi } \\
d & =\text { Tingkat Kepercayaan atau }
\end{array}
$$

Ketepatan yang diinginkan $\quad(0,05)$

Hasilnya, adalah sebagai berikut:

$$
\begin{aligned}
n= & \frac{90}{1+90\left(0,05^{2}\right)} \text { maka, } \\
& n=73 \text { Sampel }
\end{aligned}
$$

Keterangan:

$$
\begin{aligned}
& n=73 \\
& N=90 \quad \text { selama } 1 \text { bulan } \\
& d=0,05
\end{aligned}
$$




\section{HASIL DAN PEMBAHASAN}

$$
\text { Berdasarkan Standar Konsil }
$$

Kedokteran Indonesia pada lembar Informed

To Consent adalah sebagai berikut :

\begin{tabular}{|c|c|c|}
\hline \multirow[t]{2}{*}{ Keterangan } & \multicolumn{2}{|c|}{$\begin{array}{c}\text { Pernyataan } \\
\text { dalam Presentase } \\
(\%)\end{array}$} \\
\hline & Sesuai & $\begin{array}{c}\text { Tidak } \\
\text { Sesuai }\end{array}$ \\
\hline $\begin{array}{l}\text { 1. Dokter Menyampaikan Diagnosis } \\
\text { Dan Prognosis Secara Rinci } \\
\text { (Standar KKI No. 1) }\end{array}$ & $\begin{array}{c}69 \\
(95 \%)\end{array}$ & $4(5 \%)$ \\
\hline $\begin{array}{l}\text { 2. Dokter Menyampaikan Pilihan } \\
\text { Pengobatan atau Penatalaksanaan } \\
\text { terhadap Kondisi Pasien (Standar } \\
\text { KKI No. 3) }\end{array}$ & $\begin{array}{c}70 \\
(96 \%)\end{array}$ & $3(4 \%)$ \\
\hline $\begin{array}{l}\text { 3. Dokter Menyampaikan Tujuan } \\
\text { Rencana Pemeriksaan atau } \\
\text { Pengobatan sesuai Prosedur } \\
\text { (Standar KKI No. 4) }\end{array}$ & $\begin{array}{c}72 \\
(99 \%)\end{array}$ & $1(1 \%)$ \\
\hline $\begin{array}{l}\text { 4. Dokter Menyampaikan Informasi } \\
\text { mengenai Keuntungan dan Resiko } \\
\text { serta Tingkat Kemungkinan } \\
\text { Keberhasilan yang akan dialami } \\
\text { Pasien setelah dilakukan Tindakan } \\
\text { (Standar KKI No. 5) }\end{array}$ & $\begin{array}{c}57 \\
(\mathbf{7 8 \%})\end{array}$ & $\begin{array}{c}16 \\
(22 \%)\end{array}$ \\
\hline $\begin{array}{l}\text { 5. Dokter Menyampaikan Rencana } \\
\text { Pengobatan tersebut adalah Upaya } \\
\text { yang Eksperimental (Standar KKI } \\
\text { No. 6) }\end{array}$ & $\begin{array}{c}71 \\
(97 \%)\end{array}$ & $2(3 \%)$ \\
\hline $\begin{array}{l}\text { 6. Dokter Menyampaikan } \\
\text { Bagaimana dan Kapan Kondisi } \\
\text { Pasien dan Akibat Sampingnya di } \\
\text { Monitor kembali (Standar KKI No. } \\
\text { 7) }\end{array}$ & $\begin{array}{c}69 \\
(95 \%)\end{array}$ & $4(5 \%)$ \\
\hline $\begin{array}{l}\text { 7. Dokter Memberikan Informasi } \\
\text { Terkait Nama Dokter Yang } \\
\text { Bertanggung Jawab Keseluruhan } \\
\text { Atas Pengobatan } \\
\text { (Standar KKI No. 8) } \\
\end{array}$ & $\begin{array}{c}72 \\
(99 \%)\end{array}$ & $1(1 \%)$ \\
\hline $\begin{array}{l}\text { 8. Dokter Memberikan Informasi } \\
\text { Mengenai Peranan Dokter Yang } \\
\text { Sedang Mengikuti Pelatihan Atan } \\
\text { Pendidikan Bila Ada Yang } \\
\text { Mengikuti Pelatihan Atau } \\
\text { Pendidikan } \\
\text { (Standar KKI No.9) }\end{array}$ & $\begin{array}{c}70 \\
(96 \%)\end{array}$ & $3(4 \%)$ \\
\hline $\begin{array}{l}\text { 9. Dokter mengingatkan pasien } \\
\text { berhak memperoleh pendapat kedua } \\
\text { dari dokter lain } \\
\text { (Standar KKI No. 11) }\end{array}$ & $\begin{array}{c}70 \\
(96 \%)\end{array}$ & $3(4 \%)$ \\
\hline $\begin{array}{l}\text { 10. Dokter Memberi Informasi } \\
\text { Perincian Biaya(Standar KKI } \\
\text { No.12) }\end{array}$ & $\begin{array}{c}68 \\
(93 \%)\end{array}$ & $5(7 \%)$ \\
\hline
\end{tabular}

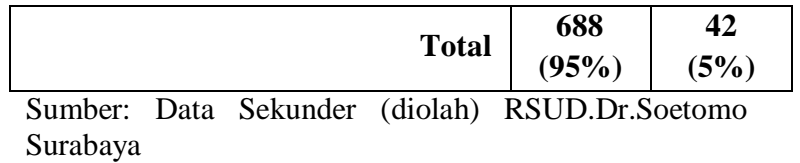

Berdasarkan data diatas menunjukkan bahwa pernyataan yang tidak sesuai terbesar adalah $22 \%$ sebanyak 16 orang yaitu pada dokter menyampaikan informasi mengenai keuntungan dan resiko serta tingkat kemungkinan keberhasilan yang akan dialami pasien setelah dilakukan tindakan.

Berdasarkan Standar Konsil

Kedokteran Indonesia pada lembar Informed Consent adalah sebagai berikut :

\begin{tabular}{|c|c|c|}
\hline \multirow[t]{2}{*}{ Keterangan } & \multicolumn{2}{|c|}{$\begin{array}{c}\text { Pernyataan dalam } \\
\text { Presentase } \\
(\%) \\
\end{array}$} \\
\hline & Sesuai & $\begin{array}{l}\text { Tidak } \\
\text { Sesuai }\end{array}$ \\
\hline $\begin{array}{l}\text { 1.Terdapat dokter pelaksana } \\
\text { tindakan (Standar KKI No. 1) }\end{array}$ & $69(99 \%)$ & $1(1 \%)$ \\
\hline $\begin{array}{l}\text { 2. Terdapat Pemberi Informasi } \\
\text { (Standar KKI No. 2) }\end{array}$ & $68(97 \%)$ & $2(3 \%)$ \\
\hline $\begin{array}{l}\text { 3. Terdapat Penerima Informasi } \\
\text { (Standar KKI No. 3) }\end{array}$ & $68(97 \%)$ & $2(3 \%)$ \\
\hline $\begin{array}{l}\text { 4. Terdapat Jenis Informasi : } \\
\text { a) Diagnosis } \\
\text { b) Dasar Diagnosis } \\
\text { c) Tindakan Kedokteran } \\
\text { d) Indikasi Tindakan } \\
\text { e) Tatacara Tindakan } \\
\text { f) Tujuan Tindakan } \\
\text { g) Resiko Tindakan } \\
\text { h) Komplikasi Tindakan } \\
\text { i) Prognosis } \\
\text { j) Alternatif Tindakan } \\
\text { Lain dan Resikonya } \\
\text { (Standar KKI No. 4) }\end{array}$ & $\begin{array}{c}70(100 \%) \\
67(96 \%) \\
70(100 \%) \\
61(87 \%) \\
62(88 \%) \\
67(96 \%) \\
68(97 \%) \\
61(87 \%) \\
61(87 \%) \\
64(91 \%)\end{array}$ & $\begin{array}{l}0(0 \%) \\
3(4 \%) \\
0(0 \%) \\
9 \\
(13 \%) \\
8 \\
(12 \%) \\
3(4 \%) \\
2(3 \%) \\
9 \\
(13 \%) \\
9 \\
(13 \%) \\
6(9 \%)\end{array}$ \\
\hline $\begin{array}{l}\text { 5. Terdapat pernyataan dari } \\
\text { dokter dan tandatangan yang } \\
\text { memberikan informasi dan } \\
\text { disertai tandatangan } \\
\text { (Standar KKI No. 5) }\end{array}$ & $67(96 \%)$ & $3(4 \%)$ \\
\hline $\begin{array}{l}\text { 6. Terdapat Identitas Pemberi } \\
\text { Persetujuan Terhadap Tindakan } \\
\text { Yang Akan Dilakukan } \\
\text { (Standar KKI No. 7) }\end{array}$ & $66(94 \%)$ & $4(6 \%)$ \\
\hline $\begin{array}{l}\text { 7. Terdapat Pernyataan Identitas } \\
\text { Pemberi Persetujuan Terhadap } \\
\text { Tindakan Yang Akan Dilakukan } \\
\text { (Standar KKI No. 7) }\end{array}$ & $66(94 \%)$ & $4(6 \%)$ \\
\hline
\end{tabular}




\begin{tabular}{|c|c|c|}
\hline $\begin{array}{l}\text { 8. Terdapat Tempat, Tanggal, } \\
\text { Bulan, Tahun, Dan Jam Dibuat. } \\
\text { (Standar KKI No. 8) }\end{array}$ & $67(96 \%)$ & $3(4 \%)$ \\
\hline $\begin{array}{l}\text { 9. Dokter Memberikan Informasi } \\
\text { Mengenai Peranan Dokter Yang } \\
\text { Sedang Mengikuti Pelatihan Atan } \\
\text { Pendidikan Bila Ada Yang } \\
\text { Mengikuti Pelatihan Atau } \\
\text { Pendidikan (Standar KKI No.9) }\end{array}$ & $60(86 \%)$ & $\begin{array}{c}10 \\
(14 \%)\end{array}$ \\
\hline Total & $\begin{array}{c}1182 \\
(94 \%)\end{array}$ & $\begin{array}{c}78 \\
(6 \%)\end{array}$ \\
\hline
\end{tabular}

Sumber: Data Sekunder (diolah) RSUD.Dr.Soetomo Surabaya

$$
\text { Berdasarkan data diatas }
$$

menunjukkan bahwa pernyataan yang tidak sesuai terbesar adalah $14 \%$ sebanyak 10 orang yaitu pada dokter memberikan informasi mengenai peranan dokter yang sedang mengikuti pelatihan atau pendidikan bila ada yang mengikuti pelatihan atau pendidikan.

$$
\text { Berdasarkan Standar Konsil }
$$

Kedokteran Indonesia pada lembar Informed

\begin{tabular}{|c|c|c|}
\hline \multirow{2}{*}{ Pernyataan } & \multicolumn{2}{|c|}{$\begin{array}{c}\text { Pernyataan dalam } \\
\text { Bentuk Presentase }(\%)\end{array}$} \\
\hline & Ya & Tidak \\
\hline $\begin{array}{l}\text { 1. Dokter memberikan } \\
\text { penjelasan tentang } \\
\text { ketidakpastian diagnosis } \\
\text { sehingga pasien memilih } \\
\text { dilakukan pemeriksaan } \\
\text { lanjutan sebelum } \\
\text { pengobatan. } \\
\text { (Standar KKI No. 2) }\end{array}$ & $3(100 \%)$ & $\mathbf{0}(\mathbf{0 \%})$ \\
\hline $\begin{array}{l}\text { 2. Dokter Memberikan } \\
\text { Pilihan Untuk Tidak } \\
\text { Dilakukan Pengobatan } \\
\text { (Standar KKI No. 3) }\end{array}$ & $3(100 \%)$ & $0(0 \%)$ \\
\hline $\begin{array}{l}\text { 3.Pasien bertanggung } \\
\text { jawab atas konsekuensi } \\
\text { pembatalan yang } \\
\text { dilakukan } \\
\text { (Standar KKI No. 10) }\end{array}$ & $3(100 \%)$ & $0(0 \%)$ \\
\hline Total & $9(100 \%)$ & $\begin{array}{c}\mathbf{0} \\
(0 \%)\end{array}$ \\
\hline
\end{tabular}
Refusal adalah sebagai berikut :
Berdasarkan data diatas menunjukkan bahwa semua pernyataan informed refusal adalah sesuai KKI. Berikut adalah perbandingan pelaksanaan informed to consent, informed consent, dan informed refusal di irna bedah flamboyan dan irna bedah gladiol :

1. Terdapat 73 sampel diperoleh hasil perhitungan checklist lembar Informed To Consent yang sesuai KKI sebesar $86 \%$ dan yang tidak sesuai sebesar $14 \%$. Data tersebut menyatakan bahwa masih terdapatnya informasi yang belum disampaikan, sehingga mempengaruhi pengisian lembar Informed Consent. Hal tersebut sesuai dengan KKI (2006) menyatakan bahwa syarat sah-nya adalah apabila pasien diberikan penjelasan / informasi dari dokter kepada pasien dalam keadaan cakap (kompeten) untuk memberikan keputusan atau persetujuan dan diberikan secara sukarela.

2. Terdapat 65 sampel diperoleh hasil perhitungan untuk checklist lembar Informed Consent yang sesuai standar KKI sebesar 95\% dan yang tidak sesuai sebesar 5\%. Data tersebut menyatakan bahwa prosedur pelaksanaan Informed Consent sudah terlaksana dengan baik, namun masih ada yang perlu ditingkatkan kembali, masih ada ketidaksesuaian berdasarkan Standar 
KKI yaitu pada terdapat dokter pelaksana tindakan, terdapat pemberi informasi, terdapat penerima informasi, jenis informasi yang disampaikan. Hal tersebut terkait peranan dokter serta penandatanganan lembar persetujuan yang telah disebutkan dalam KKI bahwa jika seorang dokter tidak memperoleh persetujuan tindakan kedokteran yang sah, maka dampaknya adalah dokter akan mengalami masalah diantaranya; hukum pidana apabila menyentuh atau melakukan tindakan terhadap pasien tanpa persetujuan dapat dikategorikan sebagai "penyerangan" atau assault. Hal tersebut dapat menjadi alasan pasien untuk mengadukan dokter kepenyidik polisi, meskipun kasus semacam ini sangat jarang terjadi.

3. Terdapat 8 sampel diperoleh hasil perhitungan untuk checklist lembar Informed Refusal yang sesuai standar KKI sebesar 100\%. Data tersebut menyatakan bahwa prosedur pelaksanaan Informed Consent sudah terlaksana dengan baik dan sudah sesuai dengan konsil kedokteran Indonesia yang memberikan 12 kunci informasi yang sesuai yang sebaiknya diberikan kepada pasien antara lain adalah nama dokter yang bertanggung jawab secara keseluruhan untuk pengobatan tersebut, serta bila mungkin nama anggota tim lainnya. Oleh karena itu tidak mencantumkan nama dokter berarti menyimpang dari kepustakaan Konsil Kedokteran Indonesia.

4. Terdapat 70 sampel diperoleh hasil perhitungan untuk checklist lembar Informed Consent yang sesuai KKI sebesar $94 \%$ dan yang tidak sesuai sebesar $6 \%$. Data tersebut menyatakan bahwa prosedur pelaksanaan Informed Consent sudah terlaksana dengan baik, namun masih ada yang perlu ditingkatkan kembali khususnya, masih ada ketidaksesuaian berdasarkan KKI yaitu pada terdapat dokter pelaksana tindakan, terdapat pemberi informasi, terdapat penerima informasi, jenis informasi yang disampaikan. Hal ini juga terakit peranan dokter serta penandatanganan lembar persetujuan yang telah disebutkan dalam KKI, bahwa jika seorang dokter tidak memperoleh persetujuan tindakan kedokteran yang sah, maka dampaknya adalah dokter akan mengalami masalah diantaranya; hukum pidana apabila menyentuh atau melakukan tindakan terhadap pasien tanpa persetujuan dapat dikategorikan sebagai "penyerangan" atau assault.

5. Terdapat 3 sampel diperoleh hasil perhitungan untuk checklist lembar Informed Refusal yang sesuai KKI sebesar 100\%. Data tersebut menyatakan bahwa prosedur 
pelaksanaan Informed Refusal sudah terlaksana dengan baik dan sudah sesuai dengan konsil kedokteran Indonesia yang memberikan 12 kunci informasi yang sesuai yang sebaiknya diberikan kepada pasien antara lain adalah nama dokter yang bertanggung jawab secara keseluruhan untuk pengobatan tersebut, serta bila mungkin nama anggota tim lainnya. Oleh karena itu tidak mencantumkan nama dokter berarti menyimpang dari kepustakaan KKI.

\section{SIMPULAN DAN SARAN}

\section{Simpulan}

1. Pada lembar Informed To Consent termasuk dalam kriteria sangat baik dengan jumlah rata-rata sebesar $95 \%$ yang sesuai dan 5\% yang tidak sesuai KKI di IRNA Bedah Flamboyan.

2. Pada lembar Informed Consent termasuk dalam kriteria sangat baik dengan jumlah rata-rata sebesar $94 \%$ yang sesuai dan $6 \%$ yang tidak sesuai KKI di IRNA Bedah Flamboyan.

3. Pada lembar Informed Refusal termasuk dalam kriteria sangat baik dengan jumlah rata-rata sebesar $100 \%$ yang sesuai KKI di IRNA Bedah Flamboyan.
4. Pada lembar Informed To Consent termasuk dalam kriteria baik dengan jumlah rata-rata sebesar $86 \%$ yang sesuai dan $14 \%$ yang tidak sesuai KKI di IRNA Bedah Gladiol.

5. Pada lembar Informed Consent termasuk dalam kriteria sangat baik dengan jumlah rata-rata sebesar 95\% yang sesuai dan 5\% yang tidak sesuai KKI di IRNA Bedah Gladiol.

6. Pada lembar Informed Refusal termasuk dalam kriteria sangat baik dengan jumlah rata-rata sebesar $100 \%$ yang sesuai KKI di IRNA Bedah Gladiol.

\section{Saran}

1. Berdasarkan hasil penelitian pada Perbandingan Pelaksanaan Informed Consent di IRNA Bedah Flamboyan dengan IRNA Bedah Gladiol RSUD Dr. Soetomo Surabaya Berdasarkan Standar Konsil Kedokteran Indonesia sebagian besar menunjukkan jumlah rata - rata yang sangat baik, namun akan sangat baik apabila hasil menunjukkan, dengan rata rata jumlah $100 \%$ dengan kriteria hasil yang sempurna.

2. Perlu di lakukan Evaluating, Controlling dan Monitoring agar 
JURNAL MANAJEMEN KESEHATAN Yayasan RS Dr. Soetomo, Volume 1, No. 1, Oktober 2015: 1-9

menghasilkan kriteria penilaian yang sangat baik dan bermanfaat besar bagi rumah sakit.

3. Perlu dilakukannya pemberian informasi secara tertulis. Misal, Penempelan Leaflet yang menjelaskan cara pengisian Berkas Rekam Medis maupun form persetujuan tindakan harus diisi dengan jelas, lengkap, dan benar yang ditujukan kepada pasien maupun Peraturan Undang Undang yang menjelaskan tentang Informed Consent.

4. Serta menjalin kerjasama dan kesadaran masing-masing individu terutama dokter, perawat, dan petugas rekam medis dalam memberikan pelayanan terhadap pasien yang sesuai dengan Visi Misi RSUD Dr. Soetomo Surabaya.

\section{DAFTAR PUSTAKA}

Budiarto, Eko. 2001. Biostatistika Untuk Kedokteran dan Kesehatan Masyarakat. Bandung : Penerbit Buku Kedokteran.

Citedin:http://www.ccrc.farmasi.ugm.ac.id /wp-content/uploads/ensiklopediakanker-payudara.pdf diakses pada 6 maret 2015

Depertemen kesehatan RI, Derektorat jenderal bina pelayanan medik. 2006. Pedoman penyelenggaraan dan prosedur rekam medis rumah sakit di Indonesia. Jakarta.

Babbie, Earl. The Practice of Social Research, Belmont: Wadswoth Co, 1992.

- Survey Research Method. Belmont. CA:Wadsworth, 1990.

Bailey, Kenneth. Method of Social Research, $4^{\text {th }}$ ed, New York: The Free Press, 1994.
Kitab Undang - Undang Negara RI Tentang Praktik Kedokteran Proposal Tahun 2012.

Komite Etik Rumah Sakit RSUD Dr. Soetomo. 2001. Etika dan Hukum Di BidangKesehatan. Surabaya : Komite Etik Rumah Sakit Umum Daerah Dr. Soetomo.

Konsil Kedokteran Indonesia. 2006. Manual Persetujuan Tindakan Medis. Edisi I: Jakarta. Konsil Kedokteran Indonesia. Cited in: http :06.93.0175_Rasmudjito.pdf Diakses pada 14 April 2014.

Penyusun. 2014. Panduan Penulisan Proposal Penelitian. Surabaya : STIKES Yayasan Rumah Sakit Dr. Soetomo.Surabaya.

Notoatmodjo, Soekidjo. 2005. Metedologi Penelitian dan Kesehatan. Edisi Revisi Jakarta : Rineka Cipta. 